Send your letters to the editor, British Dental Journal, 64 Wimpole Street, London W1G 8YS E-mailbdj@bda.org

Priority will be given to letters less than 500 words long. Authors must sign the letter, which may be edited for reasons of space.

\section{The method of choice}

Sir, I read with interest the hypothesised case by W. G. Brands (BDJ 2006; 201: 207 210) for a dentist planning for periodontal treatment in the mandible. Dr Brands appears to infer that adequate anaesthesia would be obtained by giving LA directly into the periodontal ligament area to achieve adequate pain control during the treatment. What he fails to understand is that the primary cause of chronic periodontitis is subgingival bacteria attached to the root surface of the affected teeth. The obvious sequelae is subgingival calculus deposition. Should not the teeth need to be adequately anaesthetised to reduce the pain of removing subgingival deposits from the R00T surfaces as opposed to the stated periodontal tissues? Therefore, is not an inferior nerve dental block the method of choice to achieve this? J. A. Taggart

Milton Keynes

Dr Brands responds: I would like to thank Dr Taggart for his/her reply to my article. of course this case was just an example of a test, used to read the mind of a reasonable patient. In this test Dr Taggart gives the perfect argument for the defence, stating there is no adequate alternative for a inferior nerve block in order to achieve pain control during periodontal treatment in the mandible. In our test this implies that a reasonable patient would have accepted the small risk of nerve damage.

If I was the lawyer for the patient I would argue that there is a new topical anaesthesia which is applied into the pocket and which claims to give adequate pain control during periodontal treatment even without an injection in the ligament. ${ }^{1}$ Moreover I would point to the study of Loomer and Perry. ${ }^{2}$ In this study the adequacy of anaesthesia for performing scaling and root planing on patients with moderate periodontal disease was evaluated. To conclude I would ask the defence whether they think every removal of calculus, even supra gingival in patients with exposed root surfaces, should be anaesthetised using an inferior nerve dental block.

As a judge I am not allowed to base my verdict on my own experience in dental practice that there is a good alternative for an inferior nerve block during periodontal treatment, so I would ask an expert witness.

\section{Oraqix by Dentsply.}

2. Loomer, P M, Perry D A. Computer-controlled delivery versus syringe delivery of local anesthetic injections for therapeutic scaling and tooth planing. J Am Dent Assoc 2004: 135: 358-365.

doi: 10.1038/sj.bdj.4814220

\section{Alumni support}

Sir, I wish to comment on the letter by Brian Lux and colleagues published in $B D J$ 2006; 201: 186.

All those at the King's College London Dental Institute at Guy's, King's College and St Thomas' Hospitals are very mindful of the illustrious history of all the dental hospitals and schools, including the Royal Dental Hospital of London School of Dental Surgery, which merged at various times to contribute to the success of the Institute. The importance of this history both today and in the future is undisputed and recognised.

Against this backdrop, it is a matter of regret that Mr Lux and his colleagues do not acknowledge the recognition of 'Guy's' in the full title of 'King's College London Dental Institute at Guy's, King's College and St Thomas' Hospitals', let alone the recognition of 'Guy's' in the name of the Institute dental alumni association - 'Guy's, King's and St Thomas' Dental Alumni Association'

Nothing endures more than change in an ever changing world. Those of today and tomorrow are saddened that some of yesteryear wish to focus on the past rather than the present and opportunities in the future. The Institute has benefited from mergers and change and will continue to seek arrangements to strengthen its standing, building on its history and many varied achievements.

As at present, meetings and other events involving groups of alumni with shared interests and links are to be encouraged. In the spirit and interests of the Dental Institute, it is hoped, however, that all its alumni will, first and foremost, support the existing alumni association and its activities.

N. H. F. Wilson CBE

London

doi: 10.1038/sj.bdj.4814221

\section{A mix up}

Sir, I read with interest your article Periodontal disease and health care costs (BDJ 2006; 201: 75) in which researchers are said to have concluded from a survey of the periodontal status of inpatients that periodontal disease had a significant effect on health care costs.

I haven't read the original research article but it strikes me that you may be mixing up cause and effect. For example diabetes causes a variety of conditions requiring in-patient care as well as rampant periodontitis. The perio problems aren't the cause of the patient's hospitalisation but a separate manifestation of the underlying disease process. The patient's perio control isn't likely to influence in-care costs in the slightest.

I assume an analysis of this argument appears in the original article.

\section{B. D. Skinner}

London

doi: 10.1038/sj.bdj.4814222

\section{More legislation required?}

Sir, it came to my attention whilst browsing in a local supermarket that pan masala is readily available for sale. Its sale is unrestricted by law in England and Wales, and there are no health warnings associated on the packaging to alert users to the dangers of chewing such a product.

The main constituent, areca nut or sopari, contains a powerful stimulant arecoline, the most widely-used worldwide. ${ }^{1}$ The pan on sale was in a ready-mixed format, consisting of areca nut, fennel, watermelon seeds, menthol, saccharin and glucose, with artificial colours (E102 and E142). It can also be mixed with slaked lime and wrapped in a betel leaf (known as a betel quid), with or without tobacco for chewing.

My concerns regarding pan stem from the large body of evidence linking it with submucous fibrosis, a premalignant 
lesion, and oral squamous cell carcinoma. ${ }^{2}$ The former has led to difficulties in intubation for general anaesthesia. ${ }^{3}$ Loss of periodontal attachment ${ }^{4}$ and obesity ${ }^{5}$ have links with the product. Other serious health problems include cardiovascular disease, diabetes mellitus and asthma. ${ }^{2}$ Unfortunately the arecoline produces dependence and addiction in its users.

A study of Bangladeshi adolescents found that few were aware of the association between pan chewing and oral cancer. ${ }^{6}$ Other workers found that pan chewing is commonly used by children living in Tower Hamlets, London. ${ }^{7}$

An Evidence-Based Dentistry article concluded that there is strong evidence associating areca nut (especially in the form of pan masala) and oral submucous fibrosis. ${ }^{8}$ I would agree with Professor Porter who provided commentary for this paper that public health promotion strategies should be implemented. I would also suggest that the availability of this potentially harmful agent should be restricted in a similar way to alcohol and tobacco. This is an area where targeted public education together with legislation could help to protect our patients' health. L. R. Stead

Bristol

1. www.drugscope.co.uk.

2. Warnakulasuriya S et al. Areca nut use: an independent risk factor for oral cancer. Br Med J 2002; 324: 799-800

3. Eipe N. The chewing of betel quid and oral submucous fibrosis and anaesthesia. Anaesth Analg 2005; 100 : 1210-1213.

4. Neely A L et al. The natural history of periodontal disease in humans: risk factors for tooth loss in caries-free subjects receiving no oral health care. J Clin Periodontol 2005; 32: 984-993.

5. Chang W C et al. Betel nut chewing and other risk factors associated with obesity amongst Taiwanese male adults. Int J Obes (Lond) 2006; 30: 359-363.

6. Prabhu N T et al. Betel quid chewing among Bangladeshi adolescents living in East London. Int $J$ Paediatr Dent 2001: 11: 18-24.

7. Farrand P et al. Prevalence, age of onset and demographic relationships of different areca nut habits amongst children in Tower Hamlets, London. $\mathrm{Br}$ Dent J 2001: 190: 150-154.

8. Ranganathan K etal. Oral submucous fibrosis: a casecontrol study in Chennai, South India. J Oral Pathol Med 2004; 33: 274-277.

doi: $10.1038 /$ sj.bdj.4814223

\section{Cinnacounselling}

Sir, I read with interest the letter by B. Littler $^{1}$ on the subject of cinnamaldehydeassociated stomatitis. This relatively uncommon condition has been recognised since the $1970 \mathrm{~s}^{2}$ and seems to have been associated with a particular brand of toothpaste now no longer available on the UK market. The literature contains well-substantiated case reports ${ }^{3}$ including one ${ }^{4}$ confirmed by mucosal biopsy and rechallenge. Cinnamon aldehydes are widely used as flavouring agents and should be considered as possible sensitisers in otherwise unexplained cases of stomatitis and peri-oral dermatitis. Chocolate contains similar compounds and patients who have experienced such lesions might be appropriately counselled.

\section{Hunter}

Cambridge

1. Littler B. Cinnamaldehyde. Br Dent J 2006; 201: 321

2. Drake TE, Maibach H I. Allergic contact dermatitis and stomatitis caused by a cinnamic aldehyde-flavored toothpaste. Arch Dermatol 1976; 112: 202-203.

3. Thyne G, Young D W, Fergusson M M. Contact stomatitis caused by toothpaste. NZDent J 1989; 382: 124-126.

4. Lamey P J, Lewis M A, Rees T D etal. Sensitivity reaction to the cinnamonaldehyde component of toothpaste. Br Dent J 1987; 163: 115-118.

doi: 10.1038/sj.bdj.4814224

\section{Help raise awareness}

Sir, a big thank you to the many dentists who responded to your recent article on organ donation by ordering organ donor leaflets for their waiting rooms and reception areas (Dentist's bid to boost donor numbers, BDJ 2006; 200: 604). There is a desperate shortage of donated organs in the UK and while more than 8,000 patients need a transplant at any one time, fewer than 3,000 operations can be performed each year. More than 400 patients die each year while waiting. Many of these deaths could be avoided if more people discussed their wishes for donation with their families and joined the NHS Organ Donor Register, and as former dentist and heart transplant patient Rob Hodgkiss observed in your article, dentists are ideally placed to help raise public awareness of the importance of organ donation by displaying leaflets in their practices. It was gratifying to see that in the weeks following publication of the article, more than 100 dentists responded to Rob's call by placing an order for leaflets and I hope that many others will be encouraged to follow suit by contacting the Organ Donor Line on 08456060400.

D. Moody

Press Officer, NHS UK Transplant Bristol

doi: 10.1038/sj.bdj.4814225

\section{Safe administration}

Sir, we read with interest the calculations made by J.V. Williams (BDJ 2006; 201: 187) regarding the amount of lignocaine (lidocaine) that can be administered safely. Although Mr Williams discusses lignocaine with adrenaline, he uses the dose limits set for plain lignocaine. The British National Formulary gives the maximum dose of lignocaine with adrenaline that can be administered as $500 \mathrm{mg}$, not $300 \mathrm{mg} .{ }^{1}$ Furthermore, Dentsply's information sheet accompanying 'Xylocaine' gives the maximum dose as $7 \mathrm{mg} / \mathrm{kg}$ rather than 4.4 $\mathrm{mg} / \mathrm{kg}$. Therefore, the maximum number of cartridges of $2 \%$ lignocaine with one in 80,000 adrenaline that can be used for an average $70 \mathrm{~kg}$ patient is just over 11 and not 6.8 as stated by Mr Williams. All dentists should be familiar with the quantity of lignocaine with adrenaline that can be administered safely and if in doubt refer to the manufacturer's guidance or a national drug formulary.

O. R. Mitchell

\section{A. J. Gibbons}

Peterborough

1. British National Formulary v.51. p 648. Pharmaceutical Press, 2006.

\section{doi: 10.1038/sj.bdj.4814226}

\section{Big red gum}

Sir, I read with interest the letter from B. Littler regarding cinnamaldehyde and severe stomatitis (BDJ 2006; 201: 321).

I have a GP friend who liked cinnamon flavoured chewing gum which is available in the USA as 'Big Red'. However, she no longer buys it because she realised it made her mouth sore. She would not describe her condition as severe, rather a stomatitis of pin prick appearance which was uncomfortable. She did a test several weeks after the stomatitis healed and the condition recurred - confirming that 'Big Red' chewing gum was the cause.

R. Pollock

Limavady

doi: 10.1038/sj.bdj.4814227

\section{MRSA reservoir}

Sir, I read with great interest the article Nosocomal transmission of methicillinresistant Staphylococcus aureus via the surfaces of the dental operatory (BDJ 2006; 201: 297-300), which concluded that MRSA contaminates the surfaces of dental equipment, and should therefore be considered a possible reservoir of MRSA infection.

This article sparked a thought for that well known coloniser of dental prostheses, the diamorphic yeast, Candida albicans. For years these microorganisms have found denture base acrylic a pleasant abode - their vacation hotspot being macerated skin creases at the angle of many a denture wearer's mouth. This is also a favourite location of Staphylococcus aureus and the resultant infection angular cheilitis. Candida share the limelight with a combination of bacteria in another infection, denture stomatitis, as shown by the work of Kulak et al. ${ }^{1}$

So back to the denture base: which other microorganisms recently in the headlines could be finding this sheltered 
environment so appealing ... MRSA

perhaps!

Should we consider dentures as a possible MRSA reservoir? More importantly should denture swabbing be included in hospitalised patients requiring investigation for possible MRSA infection?

Dare prosthodontists take the research further?

L. Thorp

By post

1. Kulak et al. Existence of Candida albicans and microorganisms in denture stomatitis patients. J Oral Rehabil 1997: 24: 788-790.

doi: $10.1038 /$ sj.bdj.4814228

\section{Aliens or colleagues?}

Sir, with reference to your recent feature Aliens or colleagues (BDJ 2006; 201: 397407), my late father Dr Hans Librowicz had applied to the then Dental Board for permission to work in this country in 1937. My father asked the clerk who told him that he had gained this permission where he could work. The clerk metaphorically stuck a pin into an imaginary map of England and it landed arguably in the most central place: Bradford. He settled there and my family is still here after 69 years.

We both became members of the BDA, but I am now retired and for that reason alone am no longer a member.

R. Leavor, née Librowicz

Bradford

doi: 10.1038/sj.bdj.4814229

\section{DCP ballot}

Sir, the Chief Executive of the BDA, when asked about extending membership of the aforesaid to DCPs (BDJ 2006; 201: 325), responded that any such decision will be up to the existing members to decide.

This must be done by ballot and not by some self-appointed committee. The British Medical Association has done something similar, and I see no need for us to differ.

Personally, I would leave the BDA (after 27 years) if DCPs were able to join.

\section{R. Balderston}

Durham

doi: 10.1038/sj.bdj.4814230

\section{Agency ignorami}

Sir, there was a time when dentists relied on the succour of nurses, whose established presence stabilised their practice, and afforded patients with the reassurance of a familiar face.

With the perpetual demand for

excellence in patient care and the increase in multi-cultural convergences, a number of practices have taken it upon themselves to employ part-timers, both domestic and foreign.

While some of these nurses have other commitments, such as training to attain relevant qualifications, others may desire the chance to specialise in fields not necessarily pertaining to dental nursing perse.

This degree of flexibility is not without its problems. Like their predecessors, it can be an incommode for the dentists if their nurses are off sick or on holiday.

The dental nurse's vital role has been given warranted status by the implementation of dental agencies that function solely for the purpose of facilitating their clients with trained staff, willing to drop everything in the spur of the moment and travel to their assigned destination.

As a subsequent result of this exigency, monopolies have spawned nationwide, promulgating a solution to the dilemma.

This lucrative commodity has them clambering over each other to offer their clientele a swift, hassle-free proviso.

Practices rely on these organisations to provide them with temps that are not only proficient in their job, but have an impeccable record in time keeping and attendance.

However, this disposable tool often comes at a high price, literally.

Not only do some of them cost an arm and a leg, but despite their bluster and bravado about being able to deliver anytime, anyplace or anywhere, dental practices can often find themselves left in the lurch by these so called 'helping hands'.

Worse case scenario, they send someone with the competence of a first grader and then have the temerity to charge for the honour of being lumbered with an ignoramus.

Is it fatuous to expect a certain degree of distinction from dental agencies that swank their business ethics in advertisements aimed at dentists who are already under enough pressure themselves?

Not really. It's about time all agencies made good on their word to deliver the optimum service, or two strikes and they should be out

\section{S. Abassalty \\ Practice Manager \\ Addlestone}

doi: 10.1038/sj.bdj.4814231 